
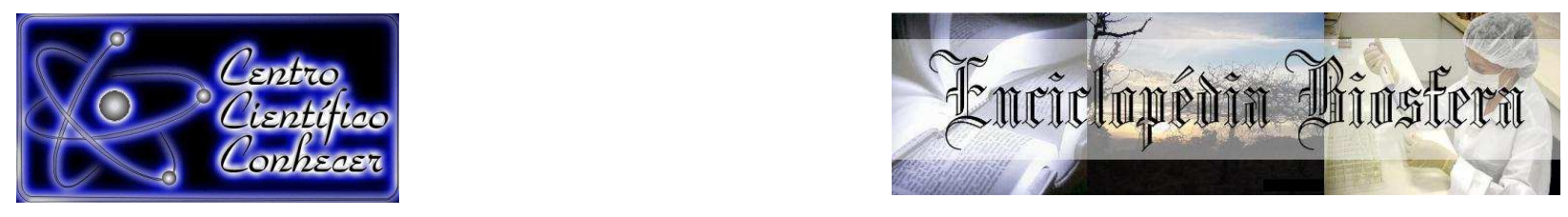

\title{
O SERTÃO MODERNO: UMA LEITURA HISTÓRICA SOBRE A RELAÇÃO ENTRE A ESTRUTURA AEROPORTUÁRIA DE GOIÂNIA E O DESENVOLVIMENTO DO CENTRO-OESTE DO BRASIL
}

Éricka Kiarelli Ribeiro Àzara Sousa'; Danilo Nogueira Magalhães ${ }^{2}$; Ludimila Stival Cardoso $^{3}$; Ycarim Melgaço Barbosa ${ }^{4}$

1 Mestranda do Programa de Pós-Graduação em Desenvolvimento e Planejamento Territorial, Pontifícia Universidade Católica de Goiás - PUC-GO (erickakr@hotmail.com)-Goiânia-GO, Brasil

2 Mestrando do Programa de Pós-Graduação em Desenvolvimento e Planejamento Territorial, Pontifícia Universidade Católica de Goiás - PUC-GO, Goiânia - GO, Brasil 3 Mestre em Comunicação pela Universidade Federal de Goiás (UFG) e Doutora em História pela UFG, Goiânia - GO, Brasil

4 Professor Doutor do Departamento de Programa de Pós-graduação stricto sensu em Planejamento e Desenvolvimento Territorial, Pontifícia Universidade Católica de Goiás - PUC-GO, Goiânia - GO, Brasil

Recebido em: 02/10/2017 - Aprovado em: 21/11/2017 - Publicado em: 05/12/2017 DOI: 10.18677/EnciBio_2017B105

\section{RESUMO}

Este artigo procede à leitura histórica da relação entre a estrutura aeroportuária de Goiânia e o desenvolvimento da região Centro-Oeste do Brasil. Partiu-se do pressuposto de que, ao longo da história, o interior do país encontrava-se separado do progresso representado pelo litoral, e que o Estado, a partir da República (1889), sentiu a necessidade de integrar social e territorialmente essa região ao restante do Brasil, como forma de garantir o progresso nacional, como ficou mais evidente na Era Vargas (1930-1945), com a chamada Marcha para o Oeste. Nesta leitura histórica ficou evidenciada a importância de uma estrutura aeroportuária para o desenvolvimento de Goiânia, bem como para o da região central do país.

PALAVRAS-CHAVE: estrutura aeroportuária, Goiânia, progresso econômico.

\section{THE MODERN BACKWOODS: A HISTORICAL INTERPRETATION ON THE RELATION BETWEEN THE AIRPORT STRUCTURE OF GOIÂNIA AND THE DEVELOPMENT OF THE CENTRAL WEST OF BRAZIL}

\begin{abstract}
This article proceeds to the historical interpretation of the creation of Goiânia's airport structure and its relation with the development of the Central West region of Brazil. It was assumed that the countryside was, throughout its history, separated from the progress represented by the coastline, and that the State, starting with the Republic (1889), felt the need to socially and territorially integrate this region to the rest of Brazil, as a way of assuring national progress, which became more evident in the Vargas Era (1930-1945), with the so-called March to the West. In this historical interpretation it was evidenced the importance of Goiânia's airport structure to its development, as well as to the central region of the country.
\end{abstract}

KEYWORDS: airport structure, economical progress, Goiânia. 


\title{
INTRODUÇÃO
}

Quando se trata de questões relacionadas ao desenvolvimento, deve-se entender que este sempre foi visto como algo a ser conquistado por meio de mudanças dentro das sociedades. Isso porque nenhuma sociedade pode sobreviver sem que produza os meios (aquilo que é útil) necessários à manutenção da própria existência (SAYEG, 2012; PESSOA; SANTOS, 2016).

De acordo com Pereira (1972), o processo de desenvolvimento é constante na medida em que os países passam a ocupar posições de destaque no contexto do capitalismo, e isso pode ser constatado por meio da mudança da qualidade de vida da população.

\begin{abstract}
O desenvolvimento é um processo de transformação econômica, política e social, através da qual o crescimento do padrão de vida da população tende a tornar-se automático e autônomo. Trata-se de um processo social global, em que as estruturas econômicas, políticas e sociais de um país sofrem contínuas e profundas transformações (PEREIRA, 1972, p. 15).
\end{abstract}

No atual contexto histórico da globalização, nota-se que, para a análise do desenvolvimento das regiões, é imprescindível considerar alguns fatores, a saber: as fronteiras, as distâncias e a inter-relação entre povos e economias (CURY; MARQUES, 2017). Isso porque, percebe-se, cada vez mais, que as fronteiras são menos determinantes, as distâncias menos limitativas, e a inter-relação entre povos e economias, maior (ALVIM et al., 2011).

Quando se aborda desenvolvimento de uma nação, isso significa, na prática, gerar riquezas. Isso ocorre por meio da exploração de atividades em diversos setores da sociedade. E esse desenvolvimento não deve ficar restrito a localidades específicas (como em regiões mais prósperas), devendo atingir, principalmente, aquelas que, ao longo do tempo, ficaram à margem (VIANNA, 2014; TARIFA; RIPPEF, 2016).

É nesse contexto que surgem as estruturas aeroportuárias. Hoje, com a importância de polos integradores de diferentes regiões, definindo, dessa forma, novas geografias regionais (CAPPA, 2013; CAPPA et al., 2017). Verifica-se que o papel dos aeroportos enquanto elemento para o desenvolvimento regional é percebido por aqueles que estão envolvidos com essa atividade e pela população em geral (PENEDA et al. 2010; CAPPA, 2013; CAPPA et al., 2017).

Segundo Peneda et al. (2010), devido a um processo sequencial, o aeroporto impacta o território de forma progressiva:

\footnotetext{
Este processo se manifesta através dos modelos de negócios desenvolvidos ao longo do tempo e irão refletir a maturidade da infraestrutura, a relevância das atividades comerciais implantadas, a integração com as redes locais e regionais e também se manifesta em termos de iniciativa e engajamento dos atores envolvidos (PENEDA et al., 2010, p. 3).
}

Conforme Oliveira (2009), os impactos que os aeroportos provocam nas regiões onde estão instalados são classificados como diretos e indiretos. Os primeiros estão relacionados com as atividades econômicas envolvidas com o aeroporto, como empresas prestadoras de serviços, empregos, receitas geradas e investimentos. Por sua vez, os impactos indiretos são paralelos às atividades diretamente ligadas ao aeroporto, quais sejam: desenvolvimento de atividades 
turísticas e em infraestrutura voltada para o transporte de cargas, além dos efeitos na economia de outros setores, como o imobiliário.

Ademais, uma infraestrutura aeroportuária exige o cumprimento de novos papeis. Observa-se, no entanto, que:

As oportunidades e os desafios econômicos representados pelos Aeroportos [...] não mudaram muito desde que surgiram, ainda na década de 1920. Os Aeroportos, como componentes vitais na cadeia de valor do transporte, oferecem velocidade, conectividade a longa distância, o que aumenta a competitividade e os modos de vida dos residentes nas áreas metropolitanas onde estão instalados. Entretanto, essa mesma cadeia de valor também impõe custos, tais como o barulho provocado pelas aeronaves, aumento no congestionamento de trânsito, demandando grande quantidade de terras e recursos. Desenvolver atividades que pudessem gerar receita não relacionadas diretamente com a Aviação, em combinação com a gestão do uso das terras foram fatores chave no sentido de atenuar tais efeitos ao longo das últimas décadas. Enquanto abordagens generalistas podem ter sido relativamente constantes, ações mais específicas para a sua implantação, orientação e escala, não foram. Um conjunto de novos atributos e funções para os Aeroportos foram se desenvolvendo no sentido de atender a essas necessidades, na medida em que a quantidade de usuários dos Aeroportos aumentava e se sofisticava (KASARDA, 2010, p. 59).

Pelo viés econômico, pode-se afirmar que a implantação de um aeroporto tem como consequência:

[...] uma grande dinamização das atividades econômicas locais. Estas causam benefícios diretos e indiretos que, por sua vez, propiciam a multiplicação de incentivos cujos resultados econômicos são importantes para a comunidade e o aeroporto. Alguns desses efeitos diretos, como as aquisições locais e os empregos gerados, apresentam inúmeras vantagens a lembrar a utilidade econômica e social da infraestrutura (SILVA, 1991, p. 129).

Nesse sentido, para pensar a estrutura aeroportuária de Goiânia, importa considerar a relação entre cidade e crescimento econômico, com base na expansão dos transportes, em especial, o aéreo.

Assim sendo, o presente artigo mostra o processo de criação dos aeroportos da cidade de Goiânia, tomando estes como elementos que evidenciam a chegada da modernidade na região central do país. Para tanto, em um primeiro momento, faz-se um recuo histórico procurando abordar o processo de ocupação da região Centro-Oeste e a necessidade de integrar social e territorialmente esse local ao restante do país, como forma de garantir o progresso nacional. Essa região foi, em alguma medida, incorporada ao Brasil pelo viés da exploração da terra e dos recursos naturais oferecidos. Logo após, aborda-se o desenvolvimento aeroportuário em Goiânia como parte do processo de desenvolvimento da região central do país.

\section{DESENVOLVIMENTO}

\section{Primeiros esclarecimentos}

A terra Brasil muito diz, sobretudo com relação à geografia; porquanto, como afirma Gaudio (2007), esta assume papel central como "mito fundador" brasileiro, baseado na natureza pródiga e na extensão territorial. Assim, o país surge como 
fruto da estrutura espacial e da preservação das fronteiras (CAVALCANTE, 2016; 2017).

Essa é uma constatação importante quando se discute o aparecimento de Goiás, capitania, já no século XVII, de forte cunho minerador (SOUZA, 1978; SEGURADO, 1984; VIEIRA, 2013). Essa realidade fez com que, nos primeiros 20 anos, o território goiano já tivesse sido praticamente todo vasculhado por bandeirantes e nações indígenas (SEGURADO, 1984).

Essa mobilidade humana confirma a perspectiva de integração econômica e territorial do país por meio da preservação e ocupação dos espaços físicos, haja vista os recenseamentos oficiais entre 1779 e 1825 (POHL, 1951). Estes apresentam os seguintes dados: crescimento da população escrava entre 1783 e 1792 , de 17.713 para 38.533 , e grande número das populações negra e mestiça parda (HOLANDA, 1967).

Esses dados tendem a ratificar a ideia de mobilidade espacial entre sertão e área litorânea, mantida pelos fluxos de comércio minerador e circulação de produtos agrícolas. Há que considerar ainda um elemento estratégico: ser meio de entrelaçamento entre localidades diferentes, visto que se situa entre dois sistemas fluviais: o Amazonas, ao Norte, e o Paraguai/Paraná, ao Sul, o que facilita o deslocamento para regiões como os estados do Pará e Maranhão e a região do Rio da Prata (LEONARDI, 1996).

Goiás torna-se, assim, parte do projeto nacional de constituição do Brasil (SEGURADO, 1984); isto é, um elemento-chave, dado que corrobora as ideias de grandeza territorial e de uso produtivo da terra, noção vinda de Portugal e existente desde o século XIV, com a instituição das sesmarias (SOUZA, 1978). Essas representaram uma lei agrária que obrigava o cultivo das terras, incentivando 0 povoamento de regiões, sobretudo a partir do século XVI, quando foi adotada no Brasil, então colônia portuguesa (RAU, 1982; MARQUES, 1987).

Não apenas a região, mas o Brasil foi visto pela metrópole como território aberto ao crescimento da produção e da ocupação, com abundância de biomassa florestal e recursos naturais inesgotáveis, terra que deveria ser, portanto, usufruída, por meio de uma exploração brutal e imediatista dos recursos naturais, o que garantia um avanço horizontal da produção (LIMA et al., 2015). Como esclarece Pádua (2004, p. 73), "[...] à medida que os solos agrícolas e pastoris tornavam-se estéreis, a fronteira avançava em direção às florestas e aos campos ainda intactos".

Goiás e parte dos estados brasileiros surgem, desse modo, por meio de um nomadismo predatório (PÁDUA, 2004; BARRETO, 2017), que garante, em alguma medida, continuidade à economia e à manutenção da estrutura social do país. Contudo, como justificar, em termos de discurso e prática, essa devastação, tomando o "sertão", do qual Goiás faz parte, como elemento identitário brasileiro?

\section{O sertão e a identidade nacional}

O sertão aparece como parte de uma tentativa de constituição de nacionalidade brasileira ainda no século XIX (CARDOSO, 2013), com a fundação do Instituto Histórico e Geográfico Brasileiro (IHGB), em 1838, que objetivava criar um sentimento de nação e forjar uma identidade. Um de seus representantes foi Couto de Magalhães, autor de "O Selvagem", obra de 1876, na qual é defendida a ideia de incorporação do selvagem à civilização, como forma de ocupar os sertões brasileiros, como expressada a seguir: 


\begin{abstract}
O territorio do nosso imenso Brazil é de 291 mil léguas quadradas. Quasi duas terças partes d'esse territorio, ou 182,400 léguas quadradas, não podem ainda hoje ser pacificamente povoadas por famílias christãs, porque estão expostas ás correrias sanguinolentas dos selvagens. Domesticar os selvagens ou fazer com que elles nos entendam, o que é a mesma cousa, equivale a fazermos a conquista pacifica de um territorio quasi do tamanho da Europa, e mais rico do que Ella. Só essa conquista vale milhões; feita ella, porém, não conseguiriamos somente a posse real da maior parte do território do imperio; conseguiríamos tambem um milhão de braços aclimados, e os unicos que se prestam ás industrias; que por muitos annos serão as unicas possiveis no interior - as extractivas e pastoris (MAGALHÃES, 1876, p. VII).
\end{abstract}

Magalhães (1876) propõe, dessa forma, a conquista dos sertões, especificamente da região central do Brasil, não por famílias cristãs incapazes de suportar a violência dos "selvagens", mas por colônias militares, que deveriam defender e formar um corpo de intérpretes que facilitassem o entendimento do português pelos indígenas. Ademais, esse autor defende o território e uma ação produtiva sobre este como principal instrumento de trabalho.

No final do século XIX, momento derradeiro do Império (1822-1889), nasce a República, regime que, segundo Cunha (1984), consiste no reino da "imbecilidade triunfante", por unir o pior da modernidade e da tradição. Essa análise é desenvolvida na obra "Os sertões", de 1902. Nesta, o autor constrói a imagem de um sertão idílico, um paraíso sobre a Terra, fundamento da nação, que tem, no sertanejo, o elemento formador da nacionalidade brasileira.

Segundo Lima (2013), o sertanejo de Euclides é um ser retrógrado, atrasado, mas não degenerado, que se põe à parte das influências negativas do litoral civilizado, sendo, portanto, elemento singular da civilização brasileira. Por isso, defende Oliveira (2000), a nacionalidade se fundamenta mais uma vez na relação homem e terra, presa a uma perspectiva evolucionista e determinista, que conjuga questões climáticas e biológicas.

Esses argumentos fundamentam o porquê das bandeiras serem vistas como principal condutor das fronteiras e da nacionalidade, sobretudo entre 1890 e 1930, como também na chamada Era Vargas (1930-1945), promovendo uma reinterpretação e valorização do bandeirante com base em uma série de obras, na qual se destacam: História Geral das Bandeiras Paulistas (1924), de Taunay; Paulística (1925), de Paulo Prado; Raça de Gigantes (1926), de Alfredo Ellis Júnior; Vida e Morte do Bandeirante (1929), de Alcântara Machado; e Marcha para Oeste (vol. 2, 1940), de Cassiano Ricardo.

Oliveira (2000) esclarece que, com base na leitura dessas obras, é possível perceber as bandeiras como movimentos de entrada no território para alargamento das fronteiras brasileiras além Tratado de Tordesilhas, o que as tornam atos de fundação da nacionalidade por meio da tarefa de ligar diversas regiões, como São Paulo à margem esquerda do rio Paraná, permitindo a penetração no interior do Brasil, onde Goiás está localizado, e do Norte.

A integração territorial representava "evolução" social. Pode-se falar em progresso econômico como a ordem do dia, e isso significava a implantação de telégrafos por todo país, tarefa dada a Cândido Rondon, e a Marcha para Oeste, de Getúlio Vargas, campanha governamental lançada às vésperas de 1938 com o objetivo de "ocupar e desenvolver o interior do Brasil" (COLLEGE; GARFIELD, 2000, p. 16). 
Tinha-se o diagnóstico de que, até então, o interior permanecia estagnado e com esparsa população, devendo-se explorar aquilo que a região oferecia, ou seja, extrair recursos naturais e humanos para assegurar a prosperidade da nação. Nesse contexto, caberia ao governo Vargas, a partir do Estado Novo (1937-1945), promover tal ação, semelhante à atuação dos bandeirantes no Período Colonial (COLLEGE; GARFIELD, 2000; D'ARAUJO, 2017).

Nota-se que o discurso e a atuação em nome do progresso econômico, defendendo a ideia de uma integração territorial e, ao mesmo tempo, social da nação brasileira, fundamentada no aproveitamento de recursos naturais, não é algo novo, mas reincidente (BARROS, 2016). Algo que se repete ad nauseam na história brasileira desde o Período Colonial (BARRETO, 2017). Passa-se à "modernidade" com a República, e chega-se à Revolução de 1930 com Getúlio Vargas.

O diferencial nos anos 1930 é a perspectiva de que esse progresso econômico ocorreria conjugado com a industrialização e com a exploração do interior, tendo como objetivo final a Amazônia. Desse modo, Vargas conseguia atuar como personagem principal de um enredo que desejava incorporar a parte central do Brasil a um projeto ideológico (COLLEGE; GARFIELD, 2000), objetivando o funcionamento do país como um todo orgânico (D'ARAUJO, 2017).

Essa "obsessão" pela modernidade via industrialização é justificada pelo contexto histórico do governo Vargas, como descrevem Cervo (2001) e Bueno e Cervo (2002): período pós Primeira Guerra Mundial; Crise de 1929, com o estopim no crack da bolsa de valores de Nova York nesse mesmo ano; e declaração de moratória da dívida externa em 1937. Esses fatos levaram o governo brasileiro a promover o progresso econômico por meio da indústria e de uma política conhecida como "substituição de importações", além do processo de cooptação de operários e da integração territorial do sertão ao país.

Todos esses elementos funcionam como componentes de uma engrenagem que representava o progresso do país. É nesse contexto que se insere Goiânia e a construção do primeiro aeroporto da cidade.

\section{Contexto histórico da fundação de Goiânia e da criação de uma estrutura aeroviária}

Em discurso proferido, por ocasião da posse como Chefe de Governo Provisório da República, em 3 de novembro de 1930, Getúlio Vargas asseverou que:

No fundo e na fôrma, a revolução [de 1930] escapou, por isso mesmo, ao exclusivismo de determinadas classes. Nem os elementos civis venceram as classes armadas, nem estas impuzeram àqueles 0 fato consumado. Todas as categorias sociais, de alto a baixo, sem diferença de idade e de sexo, comungaram em um idêntico pensamento fraterno e dominador: - a construcção de uma Pátria nova, igualmente acolhedora para grandes e pequenos, aberta á colaboração de todos os seus filhos (BRASIL, 2009, p. $51)$.

A construção dessa "Pátria nova" significava, para Vargas, o estabelecimento de um desenho institucional que objetivava cooptar camadas populares ao discurso do governo. Ao forjar parceria com a sociedade, enfraquecia a influência das elites tradicionais e das oligarquias, configurando uma rede de interesses controlada pelo poder público e ordenada pelo princípio da presença em uma categoria de ocupação (VASCONCELLOS, 2017). Em outros termos, a cidadania, a partir de então, estaria 
associada a um "[...] sistema de estratificação ocupacional definido por norma legal" (DINIZ, 1999, p. 26).

Esse arranjo, ademais, prossegue Diniz (1999), serve para reconstruir administrativamente o Brasil por meio do comércio e da indústria, sobretudo entre os anos de 1933 e 1939, período de maior desenvolvimento industrial. No que se refere à política comercial, o programa de Vargas visava promover acordos comerciais que estimulassem o crescimento da produção e das exportações para novos mercados.

Seguindo esse escopo, tem-se o Estado Novo (1937-1945). Nesse período, Vargas assume a tarefa de desenvolver economicamente o país para torná-lo uma grande potência, com capacidade militar de garantir a defesa e a segurança (D'ARAUJO, 2017). Por conseguinte, suspendeu o pagamento da dívida externa, em 1937, com o objetivo de aumentar a concentração de recursos econômicos e favorecer as relações comerciais do Brasil, além de negociar acordo com os Estados Unidos para treinamento da patrulha do litoral (D'ARAUJO, 2017).

Nota-se, desse modo, o viés pelo qual a sociedade brasileira foi inserida na história política nacional, como mão de obra, principalmente para a indústria. Os trabalhadores possuíam direitos trabalhistas, representados pela Consolidação das Leis Trabalhistas, de 1943, mas não possuíam direitos políticos e liberdade ( DINIZ, 1999; D'ARAUJO, 2017).

Goiânia estava inserida nesse contexto nacional. Segundo Haddad e Moura (2016), fundada em 1933 para ser a nova capital de Goiás, a cidade estruturou-se como parte do projeto varguista de Marcha para o Oeste, considerada a grande primeira ação. Foi construída de forma planejada para abrigar 50 mil habitantes, não possuía tendência a crescimento populacional, o que se alterou com a construção de Brasília, na década de 1960, convertendo-se em polo de atração social em razão do desenvolvimento do agronegócio no Centro-Oeste (REZENDE et al., 2015).

Percebe-se, pois, que Goiânia surgiu como parte de uma política que visava ocupar o interior do Brasil, integrando territorial e socialmente o país. Seguindo esse objetivo, chega-se à construção do primeiro aeroporto da cidade, este visto como componente dessa engrenagem (PORTO, 2005).

Porto (2005) explica que o transporte aéreo na década de 1930 ainda não era visto em todas as possibilidades, havendo resistência por parte do governo Pedro Ludovico. Essa situação alterou-se com o apoio do Exército na construção do primeiro aeroporto da cidade, apesar de toda a crença dos engenheiros Coimbra Bueno e do projetista urbano Atílio Corrêa Lima.

Ainda segundo Porto (2005), a Campanha Nacional de Aviação, com o lema "Dêem Asas ao Brasil", patrocinada por Assis Chateaubriand, promoveu a criação do primeiro aeroclube de Goiás, em 1937, pelas mãos dos irmãos Coimbra Bueno. Dois anos após esse fato, Getúlio Vargas doou um avião à primeira escola de aviação de Goiânia. Contudo, foi somente por meio da instalação dos serviços prestados pelo Correio Aéreo Militar (CAM) que o estado de Goiás diminuiu o isolamento e as distâncias em relação a outras regiões do país. Exemplo dessa realidade é a primeira linha de voos comerciais a pousar em Goiânia: o prolongamento da rota São Paulo-Uberaba, realizada pela Viação Aérea São Paulo (VASP) ${ }^{1}$, com

\footnotetext{
1 A Vasp deixou de operar em 2005, "devido à cassação de sua licença pelo Departamento de Aviação Civil (DAC), antigo agente de fiscalização do setor, substituído pela Anac" (TADEU et al., 2010 , p. 3). Os motivos da cassação foram estes: não pagamento de despesas a fornecedores, elevados custos operacionais e baixa ocupação de seus aviões (TADEU et al., 2010).
} 
subvenção do governo federal, que objetivava expandir o mercado consumidor do estado.

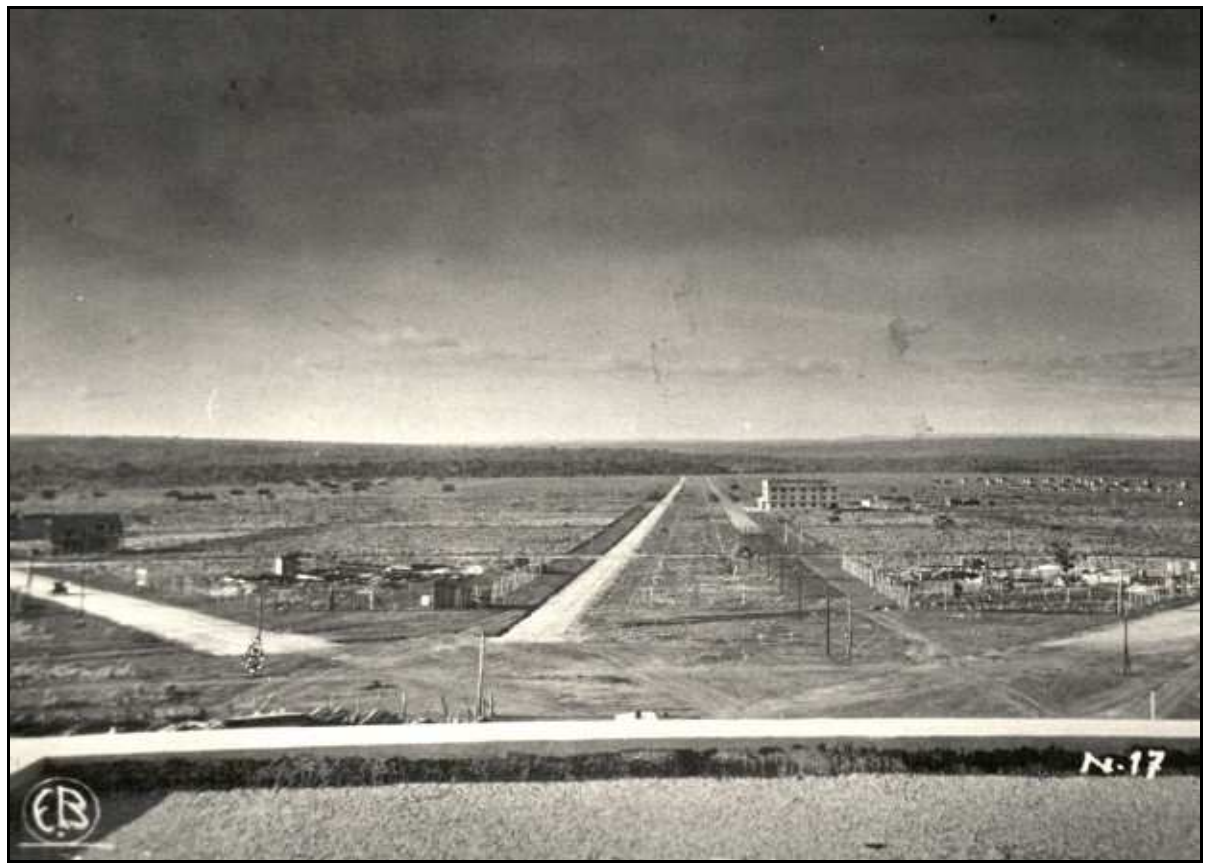

FIGURA 1. Vista do primeiro aeroporto de Goiânia, em 1937. Foto de Eduardo Bilemjian/ Divisão de Patrimônio Histórico da Secretaria de Cultura.

Fonte: G1 GOIÁS (2013).

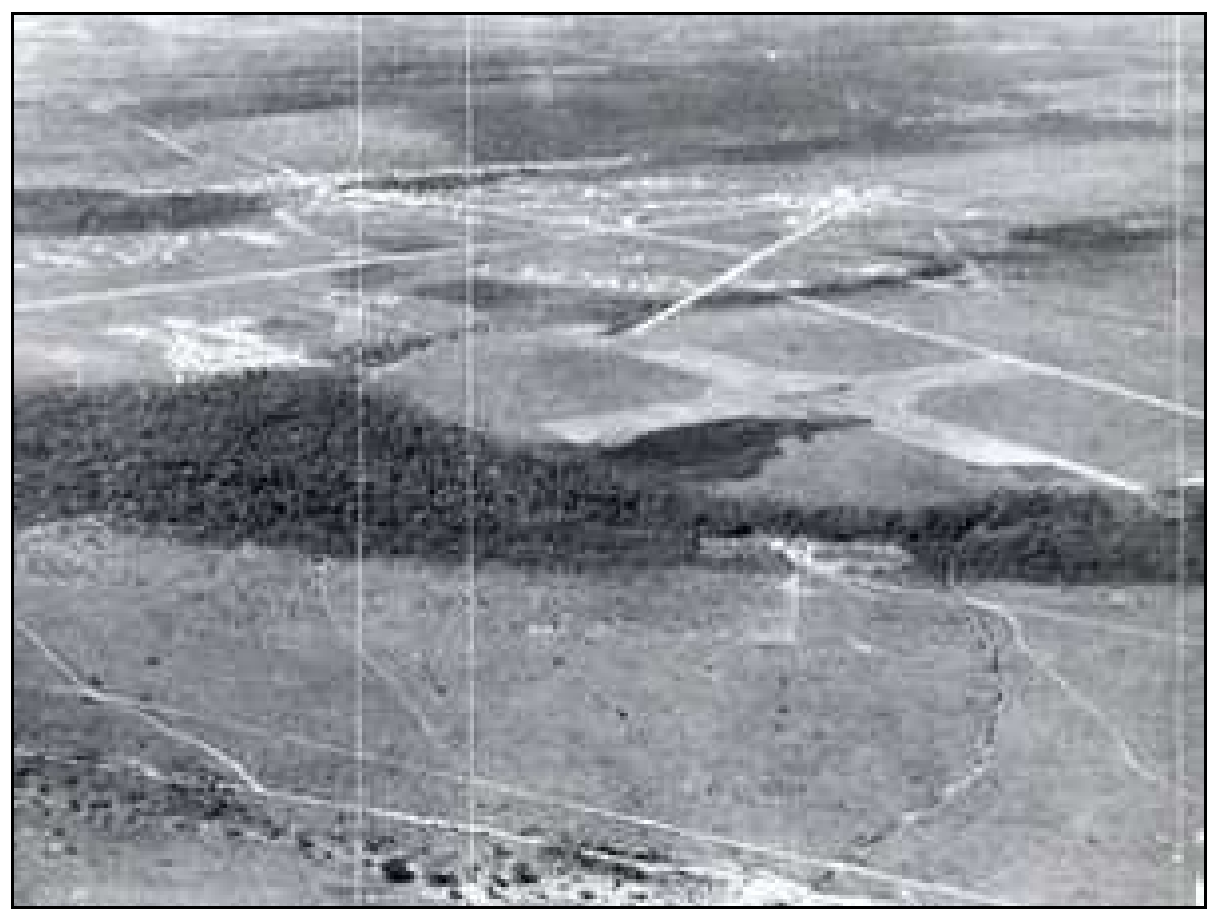

FIGURA 2. Vista aérea do primeiro aeroporto de Goiânia, em 1937. Foto de Eduardo Bilemjian/ Divisão de Patrimônio Histórico da Secretaria de Cultura.

Fonte: G1 GOIÁS (2013). 
Na Figura 2, nota-se que a pista é em formato de cruz, sendo o centro o local onde atualmente se localiza a Praça do Avião, Setor Aeroporto. Esse aeroporto fazia parte do plano inicial de Atílio Corrêa Lima, que visava construí-lo em uma região próxima ao centro da cidade. Devido à localização do empreendimento, o governo decidiu, na década de 1950, lotear a região pelo Decreto-Lei no 11 (GONÇALVES, 2002). Em 1955, surgiram as primeiras casas ao redor da pista de pouso, embora o decreto de aprovação do loteamento (90-A) datasse de 30 de julho de 1938 (MOREIRA, 2005).

Moreira (2005) esclarece que parte dessa área foi doada à Legião Brasileira de Assistência, sociedade civil de proteção à maternidade, sendo parcelada com o nome de Vila Cristo Redentor. Porém, em 1955, o então prefeito João Paulo Teixeira Filho decidiu incorporar ao Setor Aeroporto a área de 183 mil metros quadrados, pelo decreto 82 , de 20 de maio de 1955.

Assim, o restante da área foi vendido como zona residencial, e os recursos provenientes dessa venda destinaram-se à criação do Banco do Estado de Goiás (BEG), aos serviços de energia de Goiânia e Anápolis e à construção do novo aeroporto no Setor Santa Genoveva ${ }^{2}$, uma gleba de terra doada pelo médico Altamiro de Moura Pacheco (OLIVEIRA; PEIXOTO, 2010). A decisão por esse novo aeroporto acelerou-se devido a "[...] um acidente ocorrido em 1952, em que um avião Bonanza caiu no quintal de uma casa, sendo que passageiros e tripulantes morreram carbonizados" (OLIVEIRA; PEIXOTO, 2010, p. 10).

De acordo com a Infraero (2017), um novo sítio aeroportuário foi escolhido na região noroeste de Goiânia, distante oito quilômetros do centro da cidade, disponibilizado oficialmente em 5 de outubro de 1955, pelo decreto $\mathrm{n}^{\circ}$ 37.851. Esse aeroporto era composto de áreas do governo federal e do fazendeiro e médico Altamiro de Moura Pacheco. Essa área totalizava aproximadamente quatro mil metros quadrados. As atividades do novo aeroporto iniciaram-se apenas em 1956, com a proposta de ser um aeroporto internacional, visto que o objetivo era fazer de Goiânia a primeira cidade no Centro-Oeste com uma estrutura aeroportuária nesses moldes.

As melhorias estruturais começaram ainda na década de 1950. Em 1958, a pista de pouso foi pavimentada e ampliada, saindo de $1.500 \mathrm{~m}$ por $30 \mathrm{~m}$ em terra para $2.200 \mathrm{~m}$ por $45 \mathrm{~m}$. Já em 1962, construiu-se um novo terminal de passageiros, com $1.200 \mathrm{~m}^{2}$. E, em 1974,0 aeroporto foi transferido à Infraero, obedecendo à portaria no 120/GM5, de 3 de dezembro de 1973 (INFRAERO, 2017).

Essa estrutura aeroportuária funcionou até 21 de maio de 2016, quando entrou em operação assistida o novo terminal de passageiros, que, segundo a Infraero (2017) apresentou 90\% de pontualidade na nova estrutura. Após 10 anos de imbróglio, o novo aeroporto entrou em funcionamento.

Tal demora, segundo Parrode (2016), ocorreu a partir de 2006, quando o Tribunal de Contas da União (TCU) percebeu indícios de irregularidades na construção. Por isso, à época, apenas $33 \%$ do cronograma foi executado. Tentou-se retomar a obra, o que ocorreu apenas em 2013, após várias consultas ao tribunal. A expectativa de entrega era para março de 2015, mas o TCU analisou os projetos de

\footnotetext{
2 "A origem do nome Santa Genoveva - que é também o nome do bairro onde está localizado o aeroporto - vem da homenagem que um dos doadores do terreno, o médico, farmacêutico, escrito e empresário Altamiro de Moura Pacheco prestou a sua mãe, Dona Maria Genoveva de Moura Pacheco, que levava o mesmo nome da santa" (INFRAERO, 2017, s.p.).
} 
infraestrutura entre fevereiro e novembro daquele ano, sendo que a inauguração do terminal ocorreu somente em 2016.

Com novas e modernas instalações em uma área construída de 34,1 mil m², conta com quatro pontes de embarque e estacionamento com 971 vagas. Com essa estrutura, Goiânia poderá receber até 6,5 milhões de passageiros por ano. Em 2015, a demanda foi de 3,31 milhões de viajantes (INFRAERO, 2017, s.p.)

Esse terminal, segundo a então presidente da República Dilma Roussef, significa à cidade de Goiânia possuir um aeroporto "coerente com o dinamismo do Estado de Goiás", o que reforça a noção de que o desenvolvimento da estrutura aeroportuária configura-se como uma ferramenta para o crescimento econômico de uma região (PARRODE, 2016). Diante disso, pode-se afirmar também que o crescimento das cidades relaciona-se com o desenvolvimento dos modais de transporte (ALVES, 2012; FERREIRA, 2013; BRASIL, 2014.).

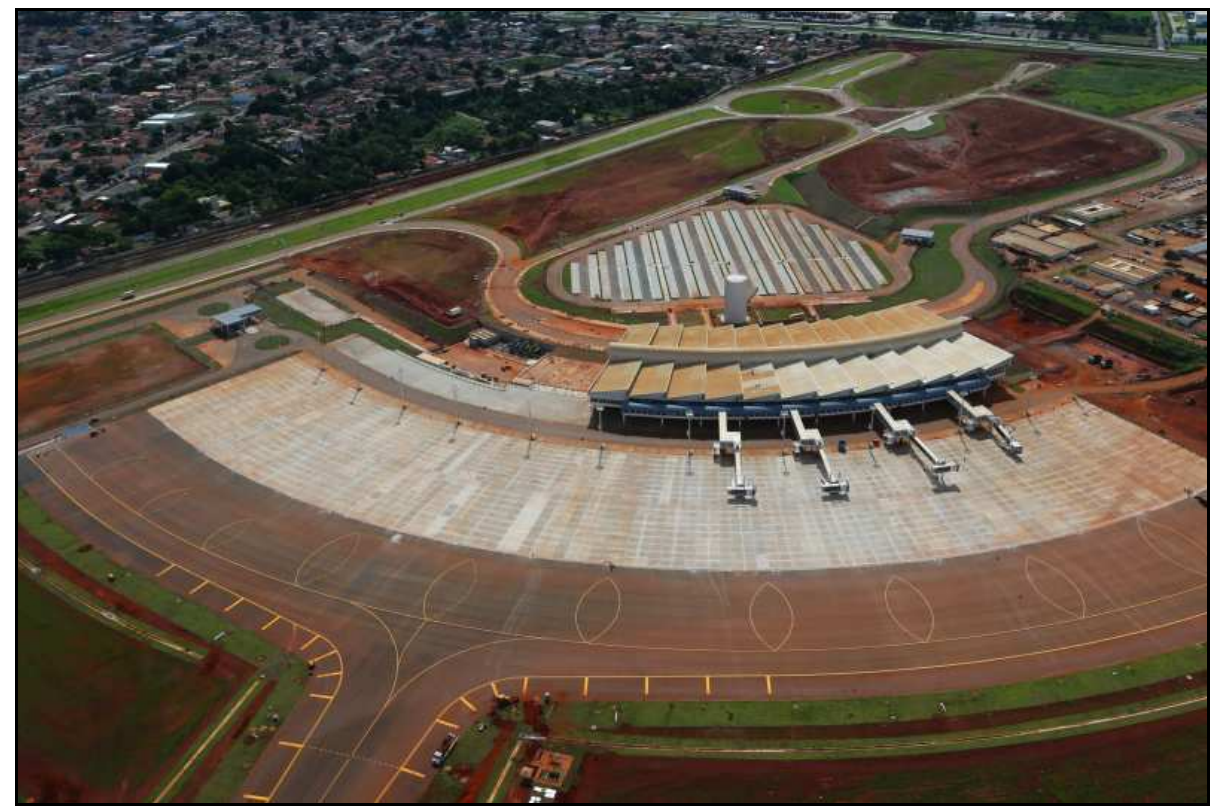

FIGURA 3. Vista do novo aeroporto de Goiânia, em 2016. Foto de Weimer Carvalho/ O Popular.

Fonte: O POPULAR (2016).

Esse tipo de projeto político institucional faz-se presente na história do Brasil antes mesmo de o país tornar-se uma República. Isso significa que a "conquista" econômica do Brasil Central representou um elemento de constituição da própria identidade nacional, repetindo-se em discursos e práticas de governos desde o Período Colonial, como bem evidenciado em Magalhães (1876), Cunha (1984) e Pádua (2004), passando pelo Período Republicano, especificamente com Getúlio Vargas e a campanha Marcha para Oeste, chegando em pleno século XXI com a política nacional desenvolvimentista dos governos Lula (2003-2010) e Dilma (20112016), embora tenha-se que admitir diferenças grandes e essenciais em cada momento histórico.

A despeito disso, observa-se que os aeroportos configuram-se como partes constituintes das áreas metropolitanas, o que promove dinamismo à economia. Isso ENCICLOPÉDIA BIOSFERA, Centro Científico Conhecer - Goiânia, v.14 n.26; p.1262 
porque um aeroporto requer toda uma infraestrutura para alimentá-lo (GÜLLER; GÜLLER, 2002; KASARDA, 2013; KASARDA; APPOLD, 2014).

De acordo com o Instituto de Pesquisa Econômica Aplicada - IPEA (2011), para se inserir nos mercados globais, uma metrópole deve cumprir três requisitos básicos, a saber: propagação, velocidade e eficiência. Isso significa que, para que uma cidade se desenvolva economicamente, é necessária a promoção de um amplo acesso para quem queira visitá-la, e isso envolve, necessariamente, dois aspectos: investimento em infraestrutura e entendimento dos marcos regulatórios do setor (PINHEIRO; FRISCHTAK, 2014; MOREIRA NETO; FREITAS, 2015; RIBEIRO et al., 2015).

No contexto atual, os aeroportos promovem vantagens competitivas dentro dos mercados regional, nacional e internacional, dado que passam a fazer parte dos processos logísticos das grandes empresas (CAPPA, 2013). Isso força, portanto, os aeroportos a adotarem uma nova dinâmica e a assumirem uma nova postura: comercial e empreendedora, indo além do transporte de passageiros e movimentação de aeronaves (TADEU; SALUM, 2012).

Devido às complexas e diversificadas atividades dos aeroportos, pode-se afirmar que o conceito de aeroportos urbanos vem mudando na medida em que mudanças ocorrem no sistema econômico (GÜLLER; GÜLLER, 2002; CAPPA, 2013; CAPPA et al., 2017). Os aeroportos não são mais vistos apenas como local de movimentação de aviões, transporte de cargas e de passageiros, mas também como um sistema complexo, em virtude do processo de globalização da economia mundial. Assim sendo, as atividades econômicas que envolvem toda uma infraestrutura aeroportuária não são mais tomadas como periféricas (KASARDA; LINDSAY, 2012).

Diante disso, pode-se inferir que, com a inauguração do novo aeroporto, Goiânia entra na rota das cidades brasileiras que desempenham papel relevante no sentido de criar oportunidades para que a população se insira no contexto global, em virtude das conexões físicas possibilitadas pela infraestrutura aeroportuária.

\section{CONSIDERAÇÕES FINAIS}

É notório o valor do transporte aéreo e das estruturas aeroportuárias para o desenvolvimento das regiões de uma nação, visto que esses estão ligados ao desenvolvimento econômico e social. Verifica-se que essa importância adquire, a cada dia, contornos maiores para a economia nacional; portanto, também para as empresas. Diante disso, nota-se que a construção de uma estrutura aeroportuária em Goiânia, com o primeiro aeroporto construído em pista de terra, configurou-se como elemento que reafirma a ideia de um "sertão moderno" integrado territorial e socialmente ao restante do país. Essa importância foi ratificada com a inauguração do novo terminal aeroviário, em 2016, com novas e modernas instalações.

\section{REFERÊNCIAS}

ALVES, G. A. A Metropolização do Espaço. In: Almeida, M. G. et al (Org.). Metrópoles: teoria e pesquisa sobre a dinâmica metropolitana. Goiânia: Cânone Editorial, 2012.

ALVIM, A. A. T. B.; ABASCAL, E. H. S.; MORAES, L. G. S. Projeto urbano e operação urbana consorciada em São Paulo: limites, desafios e perspectivas. 
Cadernos Metrópole, São Paulo, v. 13, n. 25, p. 213-233, jan./jul. 2011. Disponível em: <http://dx.doi.org/10.1590/5988>. doi: 10.1590/5988.

BARRETO, M. P. Mata Atlântica e o ensino de História: da pré-história ao período colonial brasileiro. Movimento Revista de Educação, Niterói, ano 4, n. 6, p. 272 305, jan./jul. 2017. Disponível em: < https://doi.org/10.22409/mov.v0i6.342>. doi: 10.22409/mov.v0i6.342.

BARROS, M. S. B. Integração Regional e a Apropriação de Recursos Naturais. Diversitas, $\quad$ v. 5, p. 275-295, 2016. Disponível em: <https://www.revistas.usp.br/diversitas/article/view/120596/117670>. Acesso em: 25 set. 2017.

BRASIL. Presidente (1931-1954). Discursos selecionados do Presidente Getúlio Vargas. Brasília: FUNAG, 2009.

BRASIL, Ministério da Integração Nacional . Plano estratégico de desenvolvimento do Centro- -Oeste (2007-2020). Brasília: MIN, 2014.

BUENO, C.; CERVO, A. L. História da política externa do Brasil. 2. ed. Brasília: Editora Universidade de Brasília, 2002.

CAPPA, J. Cidades e aeroportos no século XXI. Campinas: Editora Alínea, 2013.

CAPPA, J.; SPERANCINI, J. H. B. S.; CUNHA, A. F. Análise do Aeroporto Internacional de Viracopos como indutor de desenvolvimento regional. Geosul, Florianópolis, v. 32, n. 64, p. 31-46, mai./ago. 2017. Disponível em: $<$ http://dx.doi.org/10.5007/\%25x>. doi: 10.5007/\%25x.

CARDOSO, L. P. C. O Lugar da Geografia Brasileira: a sociedade de Geografia do Rio de Janeiro entre 1883 e 1945. São Paulo: AnnaBlume, 2013.

CAVALCANTE, T. L. V. A Interculturalidade Crítica como possibilidade para um diálogo sobre as territorialidades no Brasil. Tellus, Campo Grande, n. 32, p. 85-101, jan./abr. 2017. Disponível em: <http://dx.doi.org/10.20435/tellus.v17i32.434>. doi: 10.20435/tellus.v17i32.434.

Colonialismo, território e territorialidade. A luta pela terra dos Guarani e Kaiowa de Mato Grosso do Sul. Jundiaí, SP: Paco Editorial, 2016.

CERVO, A. L. Hegemonia coletiva e equilíbrio: a construção do mundo liberal (18151871). In: SARAIVA, J. F. S. (Org.). Relações Internacionais - dois séculos de história: entre a preponderância europeia e a emergência americano-soviética (1815-1947). Brasília, DF: Ibri, 2001.

COLLEGE, B.; GARFIELD, S. As raízes de uma planta que hoje é o Brasil: os índios e o Estado-Nação na Era Vargas. Revista Brasileira de História, São Paulo, v. 20, no 39, p. 15-42, 2000. DOI: <http://dx.doi.org/10.1590/S0102-01882000000100002>. doi: $10.1590 /$ S0102-01882000000100002 
CUNHA, E. da. Os Sertões. São Paulo: Três, 1984.

CURY, M. J. F.; MARQUES, J. A. L. F. A cidade inteligente: uma reterritorialização. Redes - Santa Cruz do Sul: Universidade de Santa Cruz do Sul, v. 22, n. 1, janeiroabril, $\quad$ p. 102-117, 2017. $\quad$ Disponível em: <http://dx.doi.org/10.17058/redes.v22i1.8476>. doi: 10.17058/redes.v22i1.8476

D’ARAUJO, M. C. Getúlio Vargas. 2. ed. Brasília: Câmara dos Deputados, Edições Câmara, 2017.

DINIZ, E. Engenharia institucional e políticas públicas: dos conselhos técnicos às câmaras setoriais. In: PANDOLFI, D. (Org.). Repensando o Estado Novo. Rio de Janeiro: FGV, 1999.

FERREIRA, L. C. G. Uma Reflexão Sobre a Expansão e a Mobilidade Urbana: uma análise do plano diretor de Goiânia - GO. OBSERVATORIUM: Revista Eletrônica de Geografia, v.5, n.15, p. 62-86, dez. 2013. Disponível em: < http://www.observatorium.ig.ufu.br/pdfs/5edicao/n15/04.pdf>. Acesso em: 28 set. 2017.

G1 GOIÁS. Conheça curiosidades sobre pontos históricos e culturais de Goiânia. 2013. Disponível em: <http://g1.globo.com/goias/noticia/2013/10/conhecacuriosidades-sobre-pontos-historicos-e-culturais-de-goiania.html>. Acesso em: 27 jul. 2017.

GAUDIO, R. S. D. Ideologia nacional e discurso geográfico sobre a natureza brasileira. Lutas Sociais (PUCSP), v. 17/18, p. 48-63, 2007.

GONÇALVES, A. R. Goiânia: uma modernidade possível. Brasília: Ministério da Integração Nacional; Goiânia: Universidade Federal de Goiás, 2002.

GÜLLER, M.; GÜLLER, M. Del Aeropuerto a la Ciudade-Aeropuerto. Barcelona: Editorial Gustavo Gili, 2002.

HADDAD, M. B.; MOURA, R. Dinâmicas de expansão do arranjo urbano-regional Brasília-Anápolis-Goiânia. Caderno Metropolitano ., São Paulo, v. 18, n. 36, p. 583603, jul. 2016. Disponível em: <http://dx.doi.org/10.1590/2236-9996.2016-3613>. doi: $10.1590 / 2236-9996.2016-3613$

HOLANDA, S. B. de. O Brasil monárquico. Tomo II. v. 3. São Paulo: Difusão Européia do Livro, 1967.

INFRAERO. Empresa Brasileira de Infraestrutura Aeroportuária. Infraero Aeroportos: Aeroporto Santa Genoveva. Histórico. Disponível em: $<$ http://www4.infraero.gov.br/aeroportos/aeroporto-de-goiania-santa-genoveva/sobreo-aeroporto/historico/>. Acesso em: 17 ago. 2017. 
IPEA. Instituto de Pesquisa Econômica Aplicada. Nota Técnica. Aeroportos no Brasil: investimentos recentes, perspectivas e preocupações. N. 05. Abril de 2011.

KASARDA, J. Airport cities: the evolution. Airport World, v. 18, n. 2, p. 24-27, apr./may 2013. Disponível em: < http://www.airport-world.com/features/airportdesign/2555-airport-cities-the-evolution.html>. Acesso em: 28 set. 2017.

KASARDA, J.; APPOLD, S. Planning a competitive aerotropolis. In: PEOPLES, J. The economics of international airline transport. Bingley, UK: Emerald Group Publishing, 2014.

- Airport City Pioneers. In: KASARDA, J. Global Airport Cities. Twickenham: Insight Media, 2010. p. 59-68.

KASARDA, J.; LINDSAY, G. Aerotrópole: o modo como viveremos no futuro. São Paulo: DVS Editora, 2012.

LEONARDI, V. P. de B. Entre árvores e esquecimentos: história social nos sertões do Brasil. Brasília: Paralelo 15 Editores, 1996.

LIMA, N. T. Um Sertão Chamado Brasil. 2. ed. São Paulo: Hucitec, 2013.

LIMA, W. T.; OLIVEIRA, A. M. L.; SILVA, I. O.; FRAGA, N. C. Revisitando os grandes temas do pensamento geopolítico brasileiro. Revista de Geopolítica, v. 6, n. 1 , p. 94-108, jan./jul. 2015. Disponível em: <http://www.revistageopolitica.com.br/index.php/revistageopolitica/article/view/122/12 >. Acesso em: 27 set. 2017.

MAGALHÃES, C. de. O Selvagem: I - Curso da Língua Geral segundo Ollendorf; II - Origens, costumes, região selvagem. Rio de Janeiro, RJ: Typographia da Reforma, 1876.

MARQUES, A. H. O. Portugal na Crise dos Séculos XIV e XV. Lisboa: Presença, 1987.

MOREIRA, J. Meu bairro: Setor Aeroporto. Jornal Diário da Manhã, Goiânia, 17 abr. 2005.

MOREIRA NETO, D. de F. FREITAS, R. V. de. A Nova Regulação Portuária. Belo Horizonte, MG: Editoria Fórum, 2015.

O POPULAR. Aeroporto de Goiânia é entregue dentro do prazo, mas liberação fica só para o fim de maio. 2016. Disponível em: <http://www.opopular.com.br/editorias/cidade/aeroporto-de-goi\%C3\%A2nia\%C3\%A9-entregue-dentro-do-prazo-mas-libera\%C3\%A7\%C3\%A3o-fica-s\%C3\%B3para-o-fim-de-maio-1.1063234>. Acesso em: 28 ago. 2017.

OLIVEIRA, A. M. V.; PEIXOTO, E. R. Tessitura da Cidade: história e memória de bairros. Seminário de História da Cidade e do Urbanismo, v. 11, n. 1, 2010. 
Disponível

<http://unuhospedagem.com.br/revista/rbeur/index.php/shcu/issue/view/63>. Acesso em: 07 dez. 2016.

OLIVEIRA, A. Transporte aéreo: economia e políticas públicas. São Paulo: Pezco, 2009.

OLIVEIRA, L. L. A conquista do espaço: Sertão e fronteira no pensamento brasileiro. In: OLIVEIRA, L. L. Americanos: representações da identidade nacional no Brasil e nos EUA. Belo Horizonte, MG: Ed. UFMG, 2000.

PÁDUA, J. A. Um sopro de destruição: pensamento político e crítica ambiental no Brasil Escravista, 1786-1888. 2. ed. Rio de Janeiro: Jorge Zahar, 2004.

PARRODE, A. Após dez anos, novo aeroporto de Goiânia será inaugurado. Jornal Opção, Goiânia, 08 maio 2016. Disponível em: <http://www.jornalopcao.com.br/ultimas-noticias/apos-10-anos-novo-aeroporto-degoiania-sera-inaugurado-65455/>. Acesso em: 07 dez. 2016.

PENEDA, M. J. A.; REIS, V. D.; MACÁRIO, M. do. R. M. R. Airport-Centered Urban Development: Concepts, Agents and Critical Factors. Portugal, Lisboa: UTL, 2010.

PEREIRA, L. C. B. Desenvolvimento e a crise no Brasil 1930/1967. Rio de Janeiro: Jorge Zahar, 1972.

PESSOA, F. M. G.; SANTOS, M. F. O capitalismo humanista como um elemento para o desenvolvimento: um regime econômico em consonância com os direitos humanos. Revista de Direito, Economia e Desenvolvimento Sustentável, Curitiba, v. 2, n. 2, p. 204-220, jul./dez. $2016 . \quad$ Disponível: <http://dx.doi.org/10.21902/2526-0057/2016.v2i2.1411> doi: 10.21902/25260057/2016.v2i2.1411.

PINHEIRO, A. C.; FRISCHTAK, C (Orgs.). Gargalos e soluções na infraestrutura dos transportes. Rio de Janeiro: FGV, 2014.

POHL, J. E. Viagem ao interior do Brasil. Rio de Janeiro: Instituto Nacional do Livro, 1951.

PORTO, N. M. L. História do transporte aéreo no Centro-Oeste brasileiro: 19301960. Goiânia, GO: Editora UCG, 2005.

RAU, V. Sesmarias medievais portuguesas. Lisboa: Editorial Presença, 1982.

REZENDE, C. A. de.; WANDER, A. E.; BONTEMPO, P. C. A importância do Distrito Federal na composição do mercado de emprego celetista da Região Centro-Oeste do Brasil. Teoria e Evidência Econômica - Ano 21, n. 44, p. 221-235, jan./jun. 2015. Disponível em: <http://dx.doi.org/10.5335/rtee.v21i44.5361>. doi: 10.5335/rtee.v21i44.5361 
RIBEIRO, L. C.; FREITAS, R. V. de.; FEIGELSON, B (Coord.). A Nova regulação da infraestrutura e da mineração: portos, aeroportos, ferrovia e rodovia. 1. ed. Belo Horizonte, MG: Editora Fórum, 2015.

SAYEG, R. Uma proposta de emenda constitucional para o capitalismo humanista na constituição federal. Revista Jurídica da Escola Superior do Ministério Público de São Paulo, v. 1, p. 09-31, 2012. Disponível em: <http://www.esmp.sp.gov.br/revista_esmp/index.php/RJESMPSP/article/view/14/3>. Acesso em: 27 set. 2017.

SEGURADO, J. T. Memória econômica e política da capitania de Goiás - 1806 . Memórias Goianas II. Goiânia, GO: Editora da Universidade Católica de Goiás/Centro de Cultura Goiana, 1984.

SILVA, A. Aeroportos e desenvolvimento. Belo Horizonte, MG: Vila Rica, 1991.

SOUZA, L. A. da S. Memória sobre o descobrimento, governo, população e cousas mais notáveis da Capitania de Goyaz. In: TELLES, J. M. Vida e Obra de Silva e Souza. Goiânia, GO: Editora Oriente, 1978.

TADEU, H. F. B.; CAMPOS, P. M. S.; SILVA, J. T. M.; MOREIRA, C. M.; PEREIRA, A. C. Logística Aeroportuária: Análises Setoriais e o Modelo de CidadesAeroportos. São Paulo: Cengage Learning, 2010.

TADEU, H. F.; SALUM, F. A. Estratégia, operações e inovação: paradoxo do crescimento. São Paulo: Cengage Learning, 2012.

TARIFA, M. R.; RIPPEF, R. Planejamento e desenvolvimento brasileiro: análise histórica sob a perspectiva tributária inserida nos Planos Nacionais de Desenvolvimento (Pnds I e II). Revista FAE, Curitiba, v. 19, n. 2, p. 6-21, jul./dez. 2016. Disponível em: <https://revistafae.fae.edu/revistafae/article/view/99/307>. Acesso em: 29 set. 2017.

VASCONCELLOS, G. F. Ideologia Curupira: análise do discurso integralista. Porto Alegre: EDIPUCRS, 2017; Recife: EDUPE, 2017.

VIANNA, S. B. Política econômica externa e industrialização, 1946-1951. In: ABREU, M. de P. (Org.). A ordem do progresso: dois séculos de política econômica no Brasil. 2. ed. Rio de Janeiro: Elsevier, 2014. p. 105-122

VIEIRA, M. V. Disputas políticas e a crise de autoridade em Goiás: a adesão das elites dirigentes goianas à independência do Brasil (1821-1822). Revista Crítica Histórica, n. 8, p. 23-43, 2013. <Disponível em: http://www.seer.ufal.br/index.php/criticahistorica/article/view/2926/pdf>. Acesso em: 28 set. 2017. 